
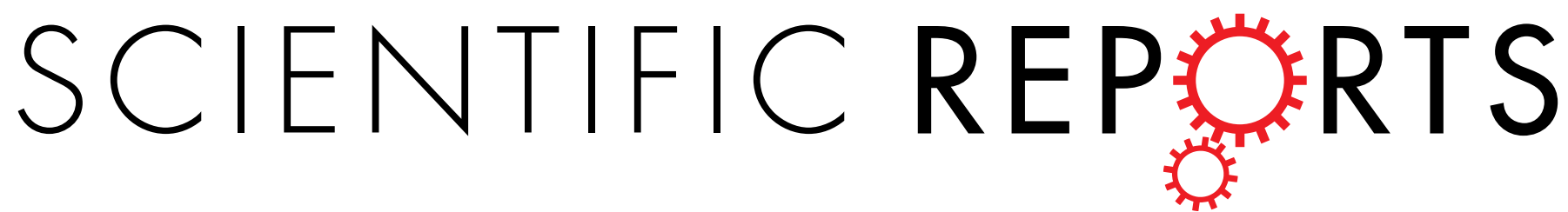

\title{
OPEN High mobility group box 1 -induced epithelial mesenchymal transition in human airway epithelial cells
}

Received: 28 July 2015

Accepted: 13 November 2015

Published: 07 January 2016
Yu-Ching Chen ${ }^{1, *}$, Sarah Statt ${ }^{2, *}$, Reen $\mathrm{Wu}^{2, *}$, Hao-Teng Chang ${ }^{3}$, Jiunn-Wang Liao ${ }^{4}$, ChienNeng Wang ${ }^{3}$, Woei-Cherng Shyu ${ }^{1} \&$ Chen-Chen Lee ${ }^{1,3,5,6}$

Epithelial-mesenchymal transition (EMT) is implicated in bronchial remodeling and loss of lung function in chronic inflammatory airway diseases. Previous studies showed the involvement of the high mobility group box 1 (HMGB1) protein in the pathology of chronic pulmonary inflammatory diseases. However, the role of HMGB1 in EMT of human airway epithelial cells is still unclear. In this study, we used RNA sequencing to show that HMGB1 treatment regulated EMT-related gene expression in human primaryairway epithelial cells. The top five upregulated genes were SNAI2, FGFBP1, VIM, SPARC (osteonectin), and SERPINE1, while the downregulated genes included OCLN, TJP1 (ZO-1), FZD7, CDH1 (E-cadherin), and $\angle A M A 5$. We found that HMGB1 induced downregulation of E-cadherin and ZO-1, and upregulation of vimentin mRNA transcription and protein translation in a dose-dependent manner. Additionally, we observed that HMGB1 induced AKT phosphorylation, resulting in GSK3 $\beta$ inactivation, cytoplasmic accumulation, and nuclear translocation of $\beta$-catenin to induce EMT in human airway epithelial cells. Treatment with PI3K inhibitor (LY294006) and $\beta$-catenin shRNA reversed HMGB1-induced EMT. Moreover, HMGB1 induced expression of receptor for advanced glycation products (RAGE), but not that of Toll-like receptor (TLR) 2 or TLR4, and RAGE shRNA inhibited HMGB1-induced EMT in human airway epithelial cells. In conclusion, we found that HMGB1 induced EMT through RAGE and the PI3K/AKT/ GSK3//3-catenin signaling pathway.

Epithelial mesenchymal transition (EMT) is a process through which epithelial cells that normally interact with basement membranes via their basal surface undergo multiple biochemical changes, causing them to differentiate into a mesenchymal-cell phenotype with enhanced migratory ability, invasiveness, and elevated resistance to apoptosis ${ }^{1,2}$. EMT is associated with embryo implantation, embryogenesis, organ development, and tissue regeneration; however, it has also been implicated in deleterious roles in chronic inflammation diseases, such as organ fibrosis, and in cancer progression and metastasis ${ }^{1}$. In chronic airway diseases, such as asthma and chronic obstructive pulmonary disease (COPD), EMT is involved in bronchial remodeling and loss of lung function ${ }^{3,4}$. Damaged airway epithelial cells that undergo EMT stimulate TGF- $\beta$ production and increase collagen synthesis, as well as cell proliferation by airway fibroblasts and myofibroblasts ${ }^{5}$. This leads to subepithelial fibrosis and lamina reticularis thickening. Reducing E-cadherin expression in EMT also triggers epidermal growth factor receptor activation and subsequent expression of thymic stromal lymphopoietin (TSLP) and thymus and activation-regulated chemokine (TARC) in the airway epithelium, which imply Th2-related allergic inflammation ${ }^{6}$. This might dampen lung dysfunction, including bronchoconstriction, mucus production, and airway remodeling ${ }^{7,8}$. In severe asthma, EMT causes subepithelial fibrosis and thickening of the bronchial wall ${ }^{9}$. In COPD, EMT causes bronchial fibrosis and reticular basement-membrane fragmentation in the large and small airways, which is associated with disease severity $^{10}$. Therefore, causes of airway structure changes constitute key hallmarks of airway remodeling ${ }^{11,12}$. Airway remodeling has been implicated in corticosteroid resistance, which hampers drug delivery to parenchymal lung

${ }^{1}$ Graduate Institute of Immunology, College of Medicine, China Medicine University, Taichung, Taiwan. ${ }^{2}$ Center for Comparative Respiratory Biology and Medicine, Internal Medicine, College of Medicine, University of California at Davis, USA. ${ }^{3}$ Institute of Basic Medical Science, College of Medicine, China Medicine University, Taichung, Taiwan. ${ }^{4}$ Institute of Veterinary Pathology, College of Veterinary Medicine, National Chung Hsing University, Taichung, Taiwan. ${ }^{5}$ Department of Microbiology and Immunology, School of Medicine, China Medicine University, Taichung, Taiwan. ${ }^{6}$ Department of Health and Nutrition Biotechnology, Asia University, Taichung, Taiwan. ${ }^{*}$ These authors contributed equally to this work. Correspondence and requests for materials should be addressed to C.-C.L. (email: leechenchen@mail.cmu.edu.tw) 


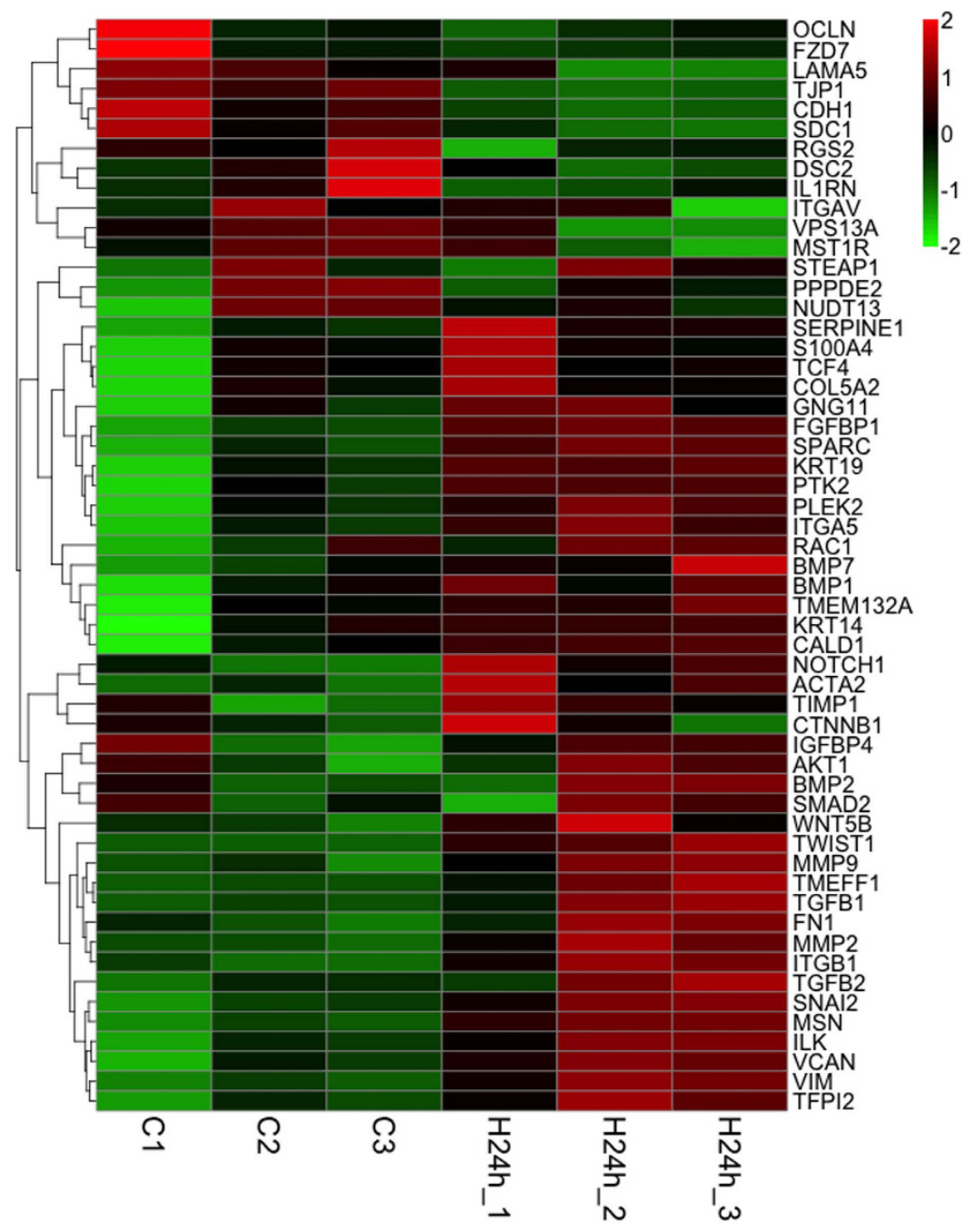

Figure 1. Heat map of EMT-related gene expression in HMGB1-treated human primary airway epithelial cells. Human primary airway epithelial cells were treated with HMGB1 $(300 \mathrm{ng} / \mathrm{mL})$ for $24 \mathrm{~h}$ and mRNA was extracted for analysis of EMT-related gene expression by RNA-sequencing assay. Red and green represent upregulation and downregulation, respectively. Three different clones of primary airway epithelial cells were used, which were isolated from different samples of human tracheobronchial tissues.

tissue and contributes to reduced response to steroid treatment in severe asthma or COPD patients and unwanted side effects resulting from prolonged high-dose steroid therapy ${ }^{13,14}$.

The high mobility group box 1 (HMGB1) protein exhibits dual functions as a nuclear protein that regulates gene expression and nucleosome stability ${ }^{15}$ and as a cytokine, which stimulates the release of pro-inflammatory cytokines, such as tumor necrosis factor (TNF) and interleukin (IL)-1 $\alpha$, IL-6, and IL-8, in monocytes ${ }^{16}$, macrophages ${ }^{17}$, and neutrophils ${ }^{18}$ during inflammation. Previous studies have showed that HMGB1 participates in the pathology of chronic pulmonary inflammatory diseases, such as asthma ${ }^{19}$ and $\mathrm{COPD}^{20}$ and that HMGB1 levels were positively associated with the severity of those diseases,. We previously reported HMGB1 involvement in allergen-induced airway remodeling in a chronic asthma mouse model ${ }^{21}$, and its induction of myofibroblast differentiation in primary human-lung fibroblasts ${ }^{22}$. Given the importance of HMGB1 in airway remodeling during chronic airway inflammatory diseases, we hypothesized that HMGB1 may directly influence airway epithelial cells by inducing EMT. Therefore, in this study, we cultured human airway epithelial cells to determine the effect of HMGB1 on EMT and the mechanisms involved. We found that HMGB1 induced mesenchymal transition in airway epithelial cells through the receptor for advanced glycation products (RAGE) and the $\beta$-catenin signaling pathway.

\section{Results}

HMGB1 induces EMT-related gene expression in human airway epithelial cells. First, we assessed whether HMGB1 induces EMT in human primary-airway epithelial cells by RNA-sequencing analysis. As shown in Fig. 1 and Table 1, we analyzed 55 EMT-related genes ${ }^{23,24}$. Compared to the control groups, HMGB1-treated cells showed significant upregulation of 22 genes and downregulation of 10 genes $(p<0.05$; Table 1$)$. The top five upregulated genes were SNAI2, FGFBP1, VIM, SPARC (osteonectin), and SERPINE1, and the downregulated 


\begin{tabular}{|c|c|c|c|}
\hline Function catagory & $\begin{array}{l}\text { Gene } \\
\text { symbol }\end{array}$ & Protein & $\begin{array}{c}\text { Fold } \\
\text { change }\end{array}$ \\
\hline \multirow[t]{12}{*}{$\begin{array}{l}\text { Extracellular matrix and cell } \\
\text { adhesion }\end{array}$} & OCLN & occludin & 0.44 \\
\hline & TJP1 & tight junction protein $\mathrm{ZO}-1$ & 0.49 \\
\hline & $\mathrm{CDH1}$ & E-cadherin & 0.56 \\
\hline & VIM & vimentin & 2.89 \\
\hline & LAMA5 & Laminin subunit alpha-5 & 0.67 \\
\hline & $S D C 1$ & syndecan-1 & 0.71 \\
\hline & DCS2 & DeCapping Scavenger2 & 0.68 \\
\hline & $I L K$ & integrin-linked kinase & 1.71 \\
\hline & $S P A R C$ & $\begin{array}{l}\text { secreted protein, acidic, cysteine-rich } \\
\text { (osteonectin) }\end{array}$ & 2.88 \\
\hline & KRT19 & keratin 19 & 1.86 \\
\hline & KRT14 & keratin 14 & 1.57 \\
\hline & $F N 1$ & Fibronectin 1 & 1.86 \\
\hline \multirow[t]{8}{*}{ Differentiation and development } & FZD7 & frizzled-7 & 0.51 \\
\hline & TCF4 & transcription factor 4 & 1.45 \\
\hline & $F G F B P 1$ & $\begin{array}{l}\text { fibroblast growth factor binding } \\
\text { protein } 1\end{array}$ & 2.94 \\
\hline & $B M P 2$ & bone morphogenetic protein 2 & 1.71 \\
\hline & SNAI2 & snail family zinc finger 2 & 3.03 \\
\hline & $T M R F F 1$ & $\begin{array}{l}\text { transmembrane protein with EGF-like } \\
\text { and two follistatin-like domains } 1\end{array}$ & 1.93 \\
\hline & NOTCH1 & $\begin{array}{l}\text { Notch homolog 1, translocation- } \\
\text { associated }\end{array}$ & 1.55 \\
\hline & TWIST1 & $\begin{array}{l}\text { twist family bHLH transcription } \\
\text { factor } 1\end{array}$ & 2.23 \\
\hline \multirow[t]{7}{*}{ Migration and motility } & $M S N$ & & 2.33 \\
\hline & SERPINE1 & $\begin{array}{l}\text { serpin E1; Plasminogen activator } \\
\text { inhibitor-1 (PAI-1) }\end{array}$ & 2.43 \\
\hline & MMP2 & matrix metallopeptidase 2 & 2.1 \\
\hline & $M M P 9$ & matrix metallopeptidase 9 & 2.0 \\
\hline & TIMP1 & tissue inhibitor of metalloproteinase 1 & 1.13 \\
\hline & PLEK & pleckstrin & 1.82 \\
\hline & TFPI2 & tissue factor pathway inhibitor 2 & 2.46 \\
\hline G-protein coupled receptor & RGS2 & Regulator of G-protein signaling 2 & 0.76 \\
\hline \multirow[t]{2}{*}{ Pro-inflammatory } & $I L 1 R N$ & interleukin-1 receptor antagonist & 0.74 \\
\hline & S100-A4 & S100-A4 & 1.54 \\
\hline \multirow[t]{2}{*}{ other } & VPS13A & $\begin{array}{l}\text { Vacuolar protein sorting-associated } \\
\text { protein } 13 \mathrm{~A}\end{array}$ & 0.69 \\
\hline & CALD1 & Caldesmon & 1.24 \\
\hline
\end{tabular}

Table 1. Genes involved in epithelial-mesenchymal transition in HMGB1 treated primary human bronchial epithelial cells.

genes included OCLN, TJP1 (ZO-1), FZD7, CDH1 (E-cadherin), and LAMA5. When airway epithelial cells undergo EMT, they show decreased expression of epithelial markers, such as the junction proteins occludin, ZO-1, and E-cadherin, and increased expression of mesenchymal markers, including vimentin and fibronec$\operatorname{tin}^{4}$. RNA-sequencing analysis showed that HMGB1 decreased occludin, ZO-1, and E-cadherin expression, and increased vimentin and SNAI2 expression in human primary-airway epithelial cells, indicating that HMGB1 might induce EMT in these cells. Next, we used real-time polymerase chain reaction (PCR) to confirm the changes in ZO-1, E-cadherin, and vimentin mRNA expression. As shown in Fig. 2A,C, HMGB1 downregulated E-cadherin and ZO-1 expression and upregulated vimentin mRNA expression in both human primary-airway epithelial cells and human bronchial epithelial cell lines (BEAS-2B cells) in a dose-dependent manner. Further investigation of protein expression showed the same trend as observed with mRNA transcription, wherein HMGB1 decreased E-cadherin and ZO-1 expression and increased vimentin protein expression in a dose-dependent manner in both human primary-airway epithelial cells (Fig. 2B) and BEAS-2B cells (Fig. 2D). Given their similar biological functions and high transfection efficiency, we chose BEAS-2B cells to analyze the mechanisms associated with HMGB1-induced EMT. Using immunocytochemistry, we verified that human airway epithelial cells expressed high levels of E-cadherin and ZO-1 and low levels of vimentin (Supplementary Figure S1), while treatment with HMGB1 $(100 \mathrm{ng} / \mathrm{mL}$ and $30 \mathrm{ng} / \mathrm{mL})$ resulted in loss of E-cadherin and ZO-1 expression and high levels of vimentin expression. TGF- $\beta 1$ is a potent EMT inducer, and many inflammatory cytokines enhance TGF- $\beta 1$-induced EMT in airway epithelial cells ${ }^{25-27}$. To clarify whether HMGB1-induced EMT might occur 
(a)

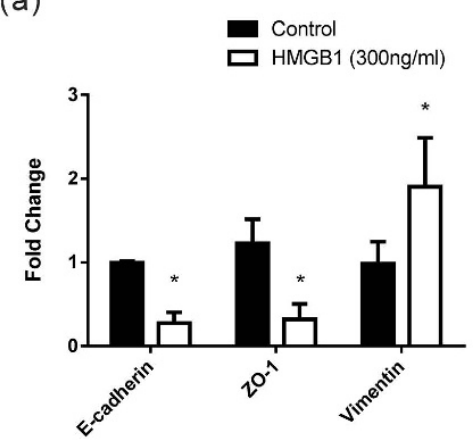

(b)
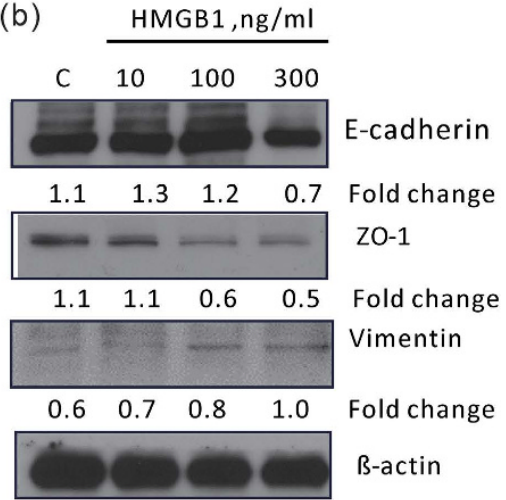

(c)
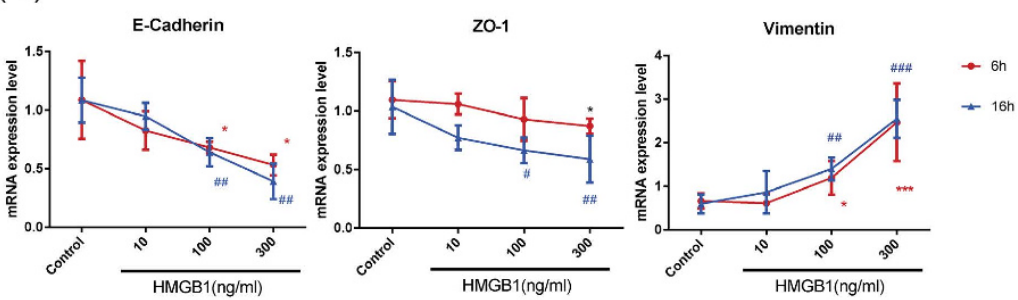

(d)
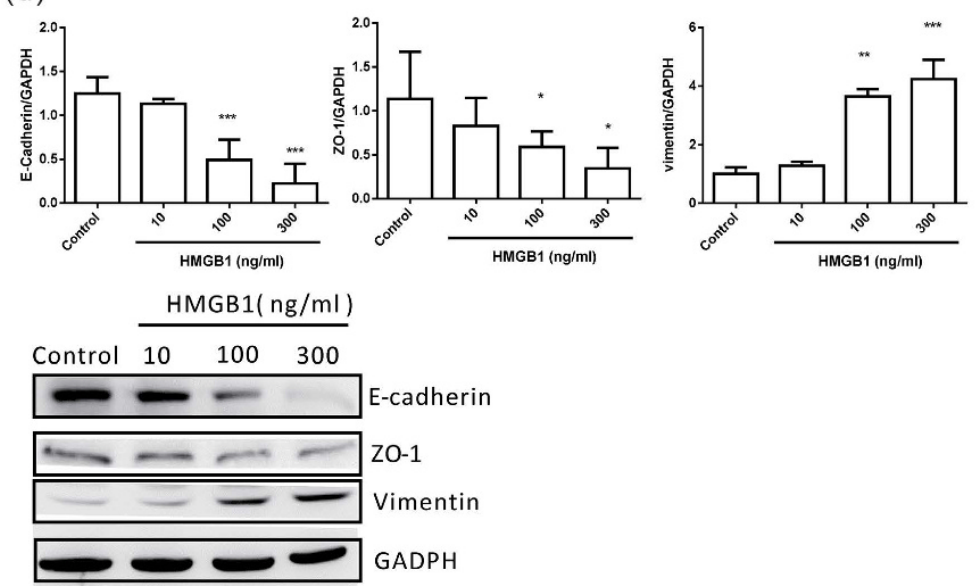

(e)
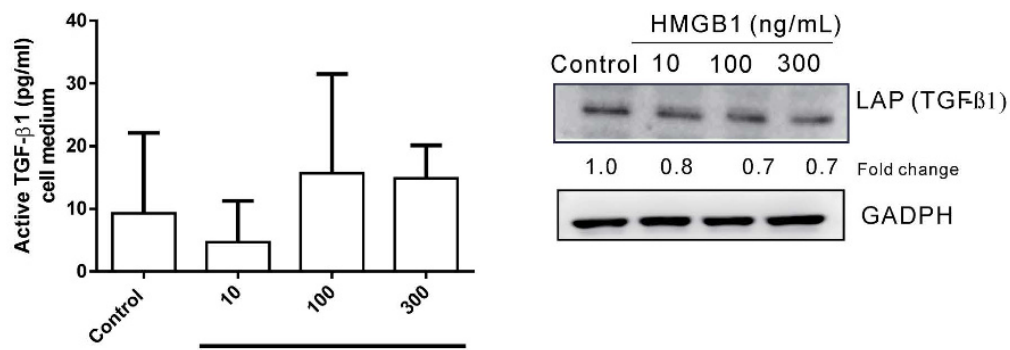

HMGB1 (ng/ml)

Figure 2. HMGB1-induced EMT in human airway epithelial cells. Human primary airway epithelial cells and BEAS-2B cells were treated with different doses of HMGB1 for mRNA analysis at different time points, and at $24 \mathrm{~h}$ for protein analysis. E-cadherin, ZO-1, and vimentin mRNA expression was detected by real-time quantitative PCR in (a) human primary airway epithelial cells and (c) in BEAS-2B cells after HMGB1 treatment $(300 \mathrm{ng} / \mathrm{mL})$ for $24 \mathrm{~h}$. E-cadherin, ZO-1, and vimentin protein expression in (b) human primary airway epithelial cells andBEAS-2B cells $(\mathbf{d})$ was assessed by western blot analysis. Data are expressed as mean \pm SD $(n=3-5) .{ }^{\star} p<0.05,{ }^{* *} p<0.01,{ }^{* *} p<0.001$, as compared with the control group. (e) TGF- $\beta 1$ expression in cell lysate (LAP) was assessed by western blot analysis and in cell medium (active form) by ELISA. Quantification of protein expression was performed using ImageJ software. Data are expressed as mean \pm S.D. $(n=4)$. In immunoblotting assay, gels have been run under the same experimental conditions. Then cropped blots were incubated with different primary antibodies for analysis of EMT markers expression. Original blots of (b) are presented in Supplementary Fig. 3. 
(a)

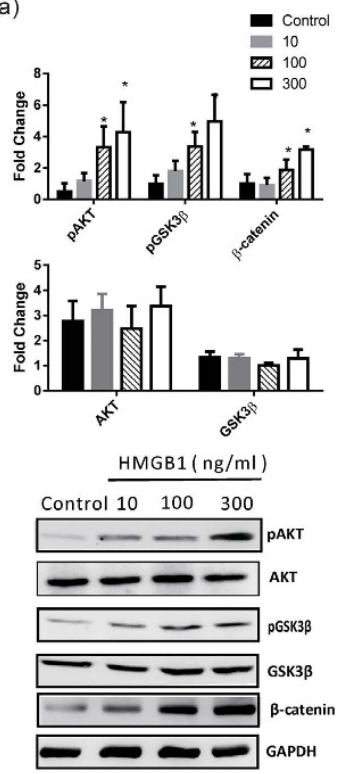

(b)

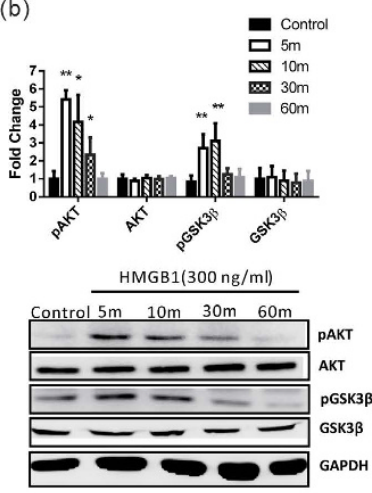

(c)

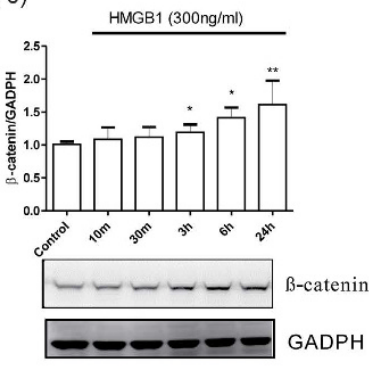

(d)

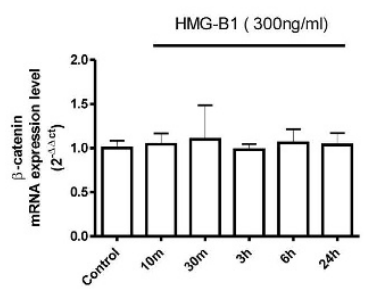

(e)
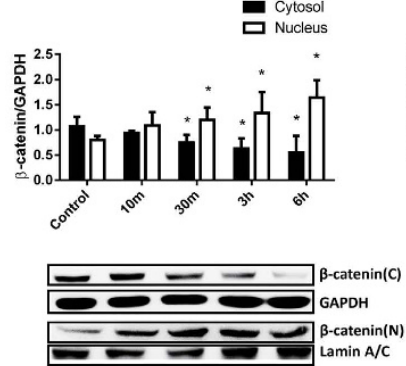

(f)
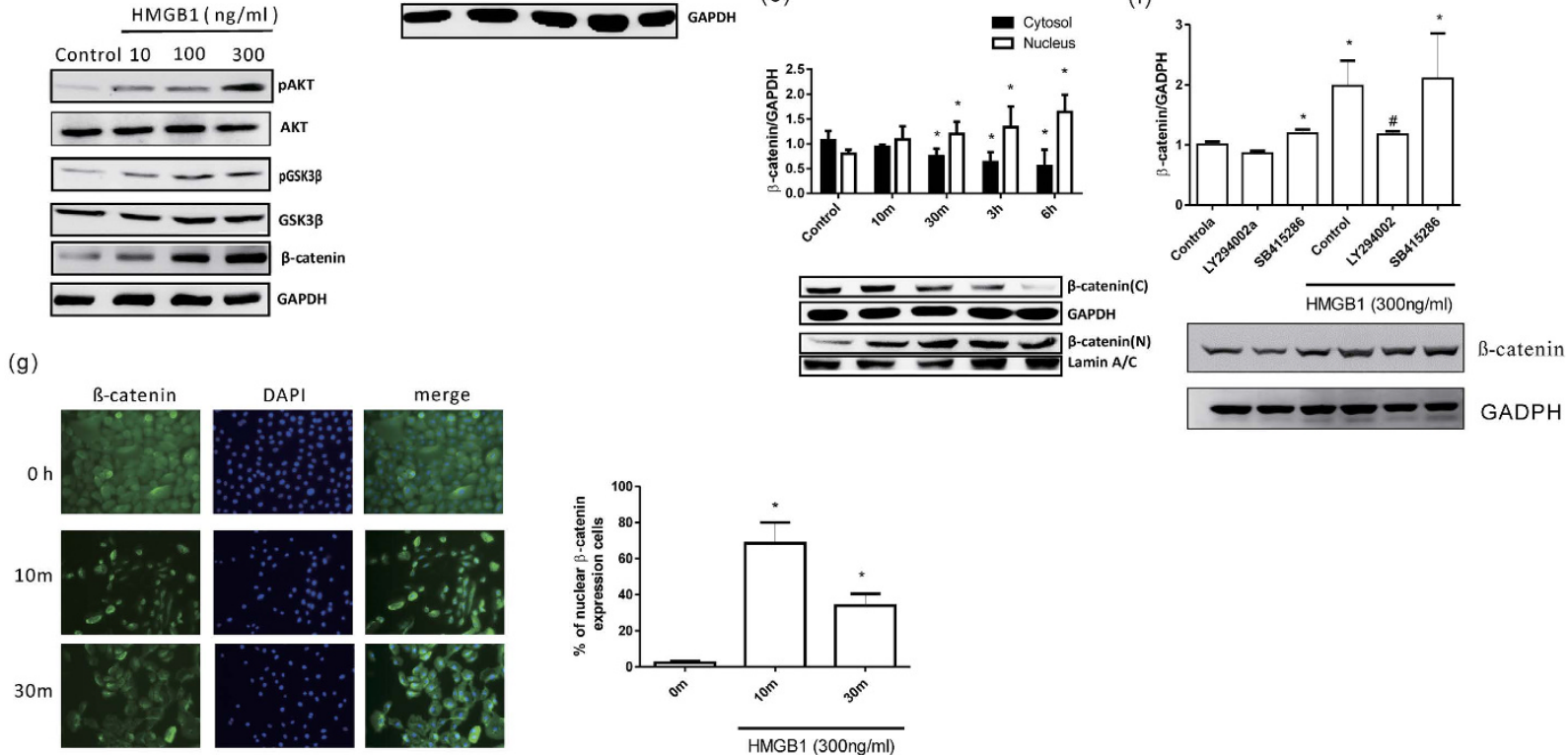

Figure 3. HMGB1-activated AKT/GSK3 $\beta / \beta$-catenin signaling pathways. (a) BEAS-2B cells were treated with different doses of HMGB1 for $10 \mathrm{~min}$ and expression of different proteins was detected by western blot. (b) BEAS-2B cells were treated with HMGB1 $(300 \mathrm{ng} / \mathrm{mL})$ for different periods and analyzed for expression of different proteins by western blot. (c) BEAS-2B cells were treated with HMGB1 $(300 \mathrm{ng} / \mathrm{mL})$ for different periods and analyzed for $\beta$-catenin expression by western blot. (d) BEAS-2B cells were treated with HMGB1 $(300 \mathrm{ng} / \mathrm{mL})$ for different periods and analyzed for $\beta$-catenin mRNA expression by real-time quantitative PCR. (e) BEAS-2B cells were treated with HMGB1 $(300 \mathrm{ng} / \mathrm{mL})$ for different periods and analyzed for nuclear and cytosolic $\beta$-catenin expression by western blot. (f) BEAS-2B cells were treated with $10 \mu \mathrm{M}$ PI3K inhibitor (LY294002) and GSK-3 3 inhibitor (SB415286) for $10 \mathrm{~min}$, and then treated with HMGB1 $(300 \mathrm{ng} / \mathrm{mL})$ for $24 \mathrm{~h}$. $\beta$-catenin expression was assessed by western blot analysis. Quantification of protein expression was performed using ImageJ software. Data are expressed as mean $\pm \mathrm{SD}$. ${ }^{*} p<0.05,{ }^{* *} p<0.01$, as compared with the control group. $\# p<0.05$, as compared the HMGB1-treatment group. $(\mathrm{A}, \mathrm{B})(n=4)$; $(\mathrm{C}-\mathrm{F})(n=3)$.

(g) Immunofluorescence staining of $\beta$-catenin (green) was detected by fluorescence microscopy. Data are expressed as mean $\pm \mathrm{SD}(n=4)$. ${ }^{\star} p<0.05$, as compared with the 0 -min grou $p$. In immunoblotting assay, gels have been run under the same experimental conditions. Then cropped blots were incubated with different primary antibodies for analysis of signaling pathway.

following TGF- $\beta$ release, we searched for evidence of the active forms of TGF- $\beta$ in culture medium and pro-form TGF- $\beta$ in cell lysate. As shown in Fig. $2 \mathrm{E}, \mathrm{F}, \mathrm{HMGB} 1$ treatment did not induce TGF- $\beta 1$ production.

HMGB1 induces EMT through the Akt/GSK-3 $\beta / \beta$-catenin pathway. Cell signaling involved in EMT includes the Ras/MAPK, PI3K/Akt, Smad, RhoB, and $\beta$-catenin pathways ${ }^{28}$. We found that HMGB1 induced AKT phosphorylation in human airway epithelial cells in a dose- (Fig. 3A) and time- (Fig. 3B) dependent manner. Given that glycogen synthase kinase-3 beta (GSK-3 $\beta$ ) is a major downstream target of AKT, we examined whether HMGB1 affects GSK-3 $\beta$ activity. As shown in Fig. 3A,B, HMGB1 inhibited GSK-3 $\beta$ activity by increasing its phosphorylation ${ }^{29}$ at ser9 without affecting total GSK-3 $\beta$ expression. Phosphorylation and inactivation of GSK- $3 \beta$ prevents $\beta$-catenin degradation and results in cytosolic accumulation and eventual nuclear translocation of $\beta$-catenin. In the nucleus, $\beta$-catenin interacts with the T-cell factor (TCF)/lymphoid enhancer-binding factor (LEF) family, leading to transcription of genes that induce EMT ${ }^{30}$. Therefore, we hypothesized that HMGB1 might induce $\beta$-catenin nuclear translocation. HMGB1 treatment induced $\beta$-catenin accumulation and nuclear translocation in a time-dependent manner in BEAS-2B cells (Fig. 3C,E). HMGB1-induced $\beta$-catenin accumulation 
(a)

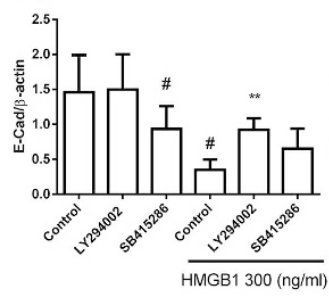

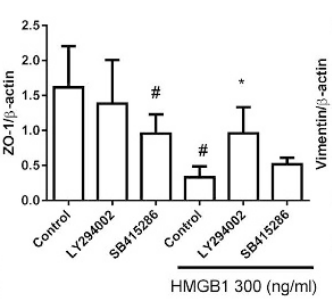

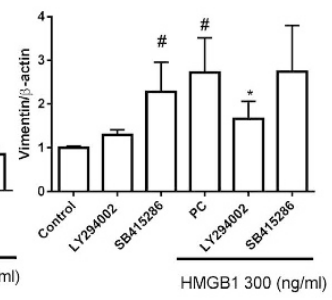

(b)

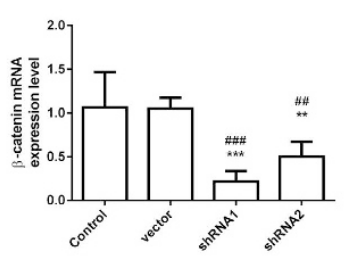

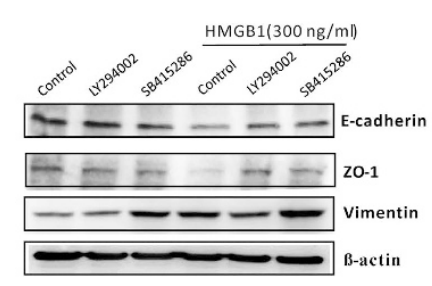

(c)

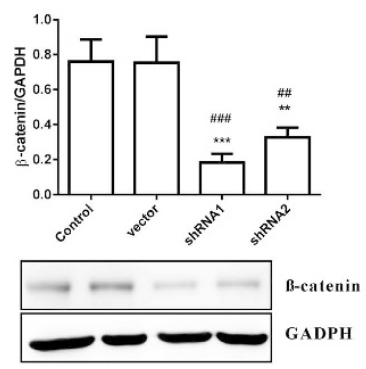

(d)

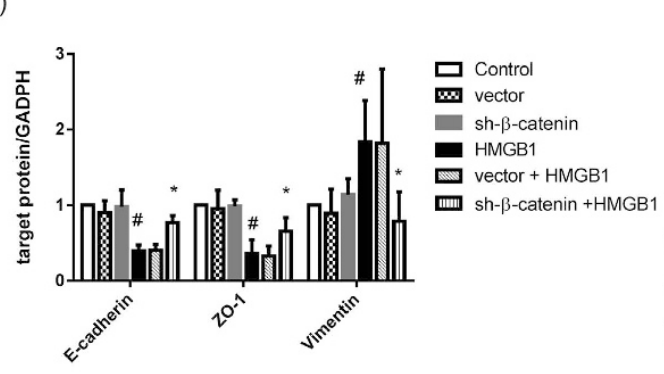

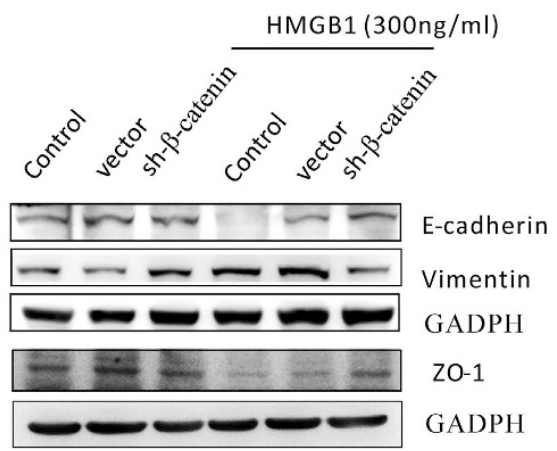

Figure 4. Inhibition of the AKT/GSK3 $\beta / \beta$-catenin signaling pathway decreased HMGB1-induced EMT. (a) BEAS-2B cells were treated with $10 \mu \mathrm{M}$ PI3K inhibitor (LY294002) and GSK-3 $\beta$ inhibitor (SB415286) for $10 \mathrm{~min}$, and then treated with HMGB1 $(300 \mathrm{ng} / \mathrm{mL})$ for $24 \mathrm{~h}$. Protein expression was detected by western blot analysis. Quantification of E-cadherin, ZO-1, and vimentin was performed using ImageJ software. Data are expressed as mean $\pm \mathrm{SD}(n=5)$. $\# p<0.05$, as compared with the control group. ${ }^{\star} p<0.05$, as compared with the HMGB1-treated group. (b) BEAS-2B cells were transduced with lentiviral-expressed $\beta$-catenin shRNA (1 MOI) for $72 \mathrm{~h}$ and selected by puromycin. The mRNA from stable clones expressing $\beta$-catenin-targeting shRNAs was analyzed by quantitative real-time PCR. Data are expressed as mean $\pm \mathrm{SD}(n=5)$. \#\# $p<0.01$, \#\#\# $p<0.001$, as compared with the control group. ${ }^{* *} p<0.01,{ }^{* *} p<0.001$, as compared with the vector group. (c) $\beta$-catenin protein expression was detected by western blot analysis in a stable $\beta$-catenin shRNA BEAS- 2 B cell clone. Quantification of protein expression was performed using ImageJ software. Data are expressed as mean \pm SD

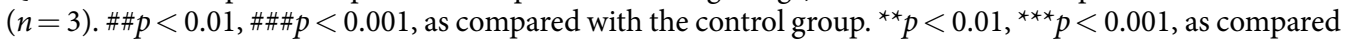
with the vector group. (d) A stable $\beta$-catenin shRNA BEAS-2B cell clone was treated with HMGB1 (300 ng/ $\mathrm{mL}$ ) for $24 \mathrm{~h}$, and protein expression of E-cadherin, ZO-1, and vimentin was detected by western blot analysis. Quantification of protein expression was performed using ImageJ software. Data are expressed as mean \pm SD $(n=4)$. $\# p<0.05$, as compared with the control group. ${ }^{\star} p<0.05$, as compared with the HMGB1 group. In immunoblotting assay, gels have been run under the same experimental conditions. Then cropped blots were incubated with different primary antibodies for analysis of signaling pathway.

did not occur through increased mRNA transcription (Fig. 3D), but rather through post-transcriptional modification. Similar to results observed in the BEAS-2B cells, human primary airway epithelial cells (Fig. 3G) showed $\beta$-catenin activation and nuclear translocation after HMGB1 treatment.

Next, we used different inhibitors to confirm whether HMGB1 induced EMT through the PI3K/AKT, GSK-3 $\beta$, and $\beta$-catenin signaling pathways (Figs 3F and 4). First, we determined whether HMGB1 induction of the PI3K/ AKT and GSK-3 $\beta$ signaling pathways was dependent upon $\beta$-catenin activation. As shown in Fig. 3F, cells treated with a GSK-3 $\beta$ inhibitor (SB415286) without HMGB1 resulted in increased $\beta$-catenin expression. Additionally, following treatment with a PI3K inhibitor (LY294002), HMGB1-induced $\beta$-catenin expression was inhibited. However, a combined treatment with HMGB1 and the GSK-3 $\beta$ inhibitor did not show any synergistic effects on $\beta$-catenin expression. Next, we observed that HMGB1-induced E-cadherin and ZO-1 downregulation and vimentin upregulation were reversed when cells were treated with a PI3K inhibitor (Fig. 4A). When cells were treated with GSK-3 $\beta$ inhibitor, which stabilizes $\beta$-catenin, E-cadherin and ZO- 1 expression decreased and vimentin expression increased in human airway epithelial cells, even in the absence of HMGB1. Similar to $\beta$-catenin expression, combined treatment with HMGB1 and the GSK-3 $\beta$ inhibitor did not show any synergistic effects on the expression of EMT markers. Next, the cells were transduced to express shRNAs targeting $\beta$-catenin. Of these, 
(a)

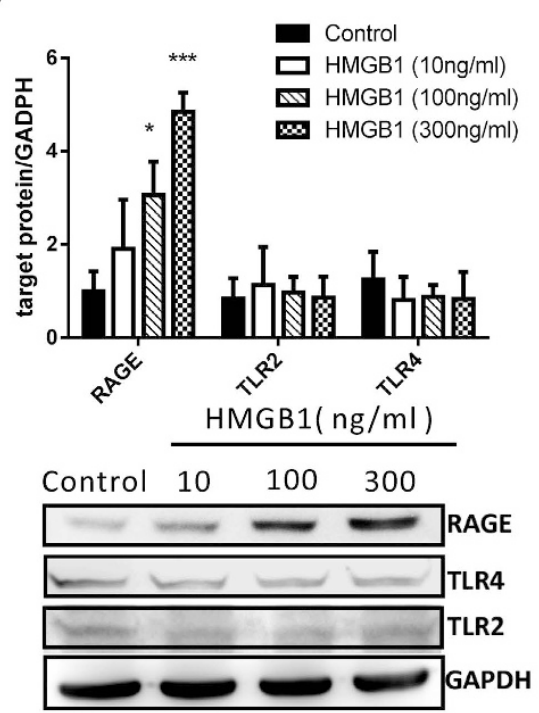

(c)

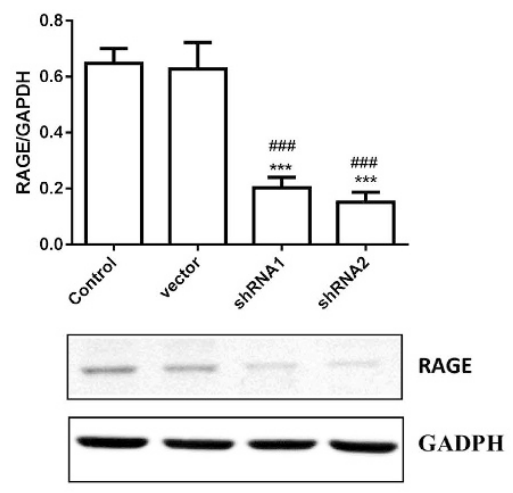

(b)

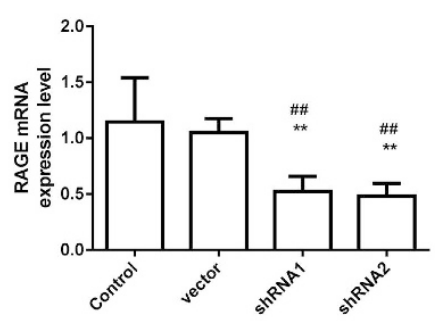

(d)

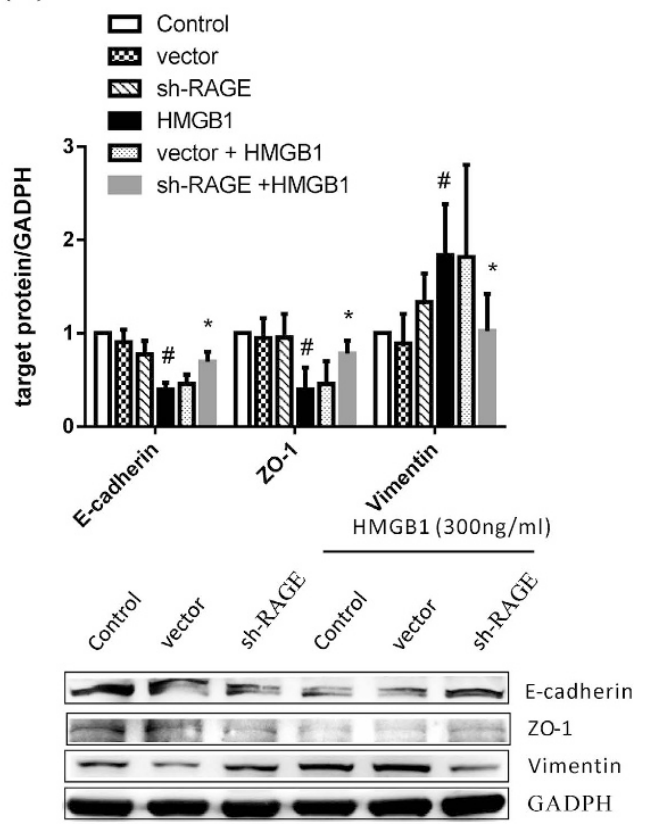

Figure 5. Induction of RAGE, but not TLR2 and TLR4 expression, in HMGB1-treated BEAS-2B cells. (a) BEAS-2B cells were treated with different doses of HMGB1 for 24h to detect expression of HMGB1 receptors by western blot analysis. Quantification of protein expression was performed using ImageJ software. Data are expressed as mean $\pm \mathrm{SD}(n=4) .{ }^{*} p<0.05,{ }^{* * *} p<0.001$, as compared with control group. (b) BEAS-2B cells were transduced with lentiviral-expressed RAGE shRNA (0.5 MOI) for $72 \mathrm{~h}$ and selected by puromycin. The mRNA from stable clones that expressed RAGE shRNA was detected by quantitative real-time PCR. Data are expressed as mean $\pm \mathrm{SD}(n=3)$. \#\# $p<0.01$, as compared with the control group. ${ }^{* *} p<0.01$, as compared with the vector group. (c) RAGE protein expression was confirmed by western blot analysis in stably expressed RAGE shRNA BEAS-2B cells. Quantification of RAGE protein expression was performed using ImageJ software. Data are expressed as mean $\pm \mathrm{SD}(n=3)$. \#\#\#p $<0.001$, as compared with the control group. ${ }^{* * *} p<0.001$, as compared with the vector group. (d) Stable clones expressing RAGE-targeting shRNAs (sh-RAGE) were treated with HMGB1 $(300 \mathrm{ng} / \mathrm{mL})$ for $24 \mathrm{~h}$ and assessed for E-cadherin, ZO-1, and vimentin protein expression by western blot analysis. Quantification of protein expression was performed using ImageJ software. Data are expressed as mean $\pm \mathrm{SD}(n=5)$. $\# p<0.05$, as compared with the control group. ${ }^{*} p<0.05$, as compared with the HMGB1 group. In immunoblotting assay, gels have been run under the same experimental conditions. Then cropped blots were incubated with different primary antibodies for analysis of signaling pathway. 
(a)

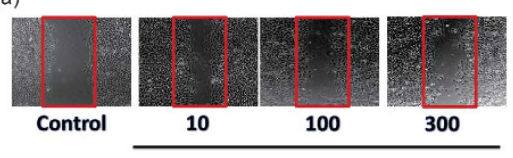

HMGB1 $(\mathrm{ng} / \mathrm{ml})$ (b)

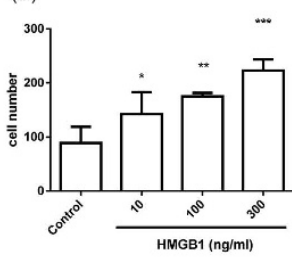

(c)

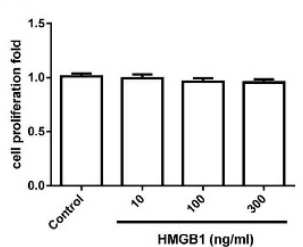

(d)

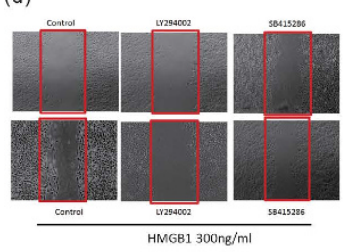

(e)

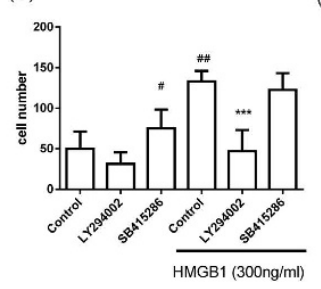

(f)

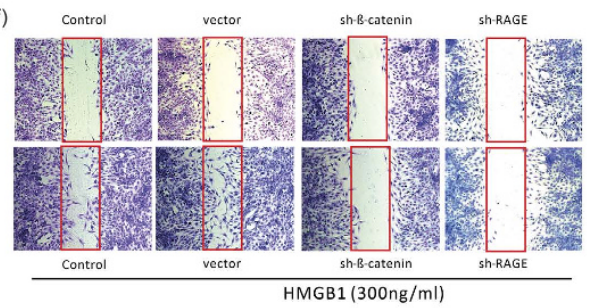

vector (g)

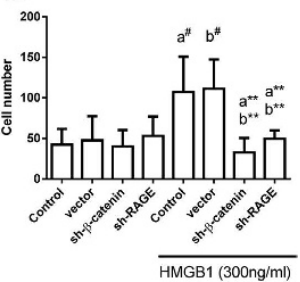

Figure 6. HMGB1 induced cell migration through activation of the RAGE/AKT/GSK3 $\beta / \beta$-catenin signaling pathway. (a) BEAS-2B cells were treated with different doses of HMGB1 for $16 \mathrm{~h}$, and cell migration was detected by in vitro scratch assay. (b) Quantification of cell migration was performed by counting the cells in the wound in four fields per sample. Data are expressed as mean $\pm \operatorname{SD}(n=5) .{ }^{\star} p<0.05,{ }^{* *} p<0.01$, ${ }^{* * *} p<0.001$, as compared with the control group, in which cells were treated with PBS. (c) BEAS-2B cells were treated with different doses of HMGB1 for $16 \mathrm{~h}$, and cell proliferation was detected by BrdU-incorporation assay. Data are expressed as mean $\pm \operatorname{SD}(n=3)$. (d) Cells were pretreated with $10 \mu \mathrm{M}$ of different inhibitors for $10 \mathrm{~min}$, and then treated with HMGB1 $(300 \mathrm{ng} / \mathrm{mL})$ for $16 \mathrm{~h}$. Cell migration was detected by in vitro scratch assay. (e) Quantification of cell migration was performed by counting the cells in the rectangle in four fields per sample. Data are expressed as mean $\pm \mathrm{SD}(n=5)$. $\# p<0.05$, \#\#p<0.01, as compared with the control group. ${ }^{* * *} p<0.001$, as compared with the HMGB1 group. (f) Stable clones expressing shRNAs targeting $\beta$-catenin (sh- $\beta$-catenin) and RAGE (sh-RAGE) were treated with HMGB1 $(300 \mathrm{ng} / \mathrm{mL})$ for $16 \mathrm{~h}$. Cell migration was detected by in vitro scratch assay. (g) Quantification of cell migration was performed by counting the cells in the red rectangle in four fields per sample. Data are expressed as mean $\pm \operatorname{SD}(n=4) \mathrm{a}^{\#} p<0.05$, as compared with the control group. $\mathrm{b}^{\#} p<0.05$, as compared with the vector group. $\mathrm{a}^{\star *} p<0.05$, as compared to the PC group. $\mathrm{b}^{* *} p<0.05$, as compared to the vector treated with HMGB1.

shRNA1-expressing cells showed significant knockdown of $\beta$-catenin mRNA and protein expression (Fig. 4B,C). In these cells, E-cadherin and ZO-1 downregulation and vimentin upregulation did not occur following HMGB1 treatment (Fig. 4D). Furthermore, $\beta$-catenin knockdown cells did not display changes in morphology or growth rate (Supplementary Figures S2C and S2D).

HMGB1-induced EMT in human airway epithelial cells involves RAGE. HMGB1 induces phagocyte activation and cell migration through binding to membrane receptors, such as RAGE, Toll-like receptor (TLR) 2, and TLR4, to activate downstream signaling pathways ${ }^{31-33}$. After treatment with HMGB1, we found that RAGE expression increased in a dose-dependent manner; however, TLR2 and TLR4 did not show any obvious changes (Fig. 5A). We silenced RAGE gene expression using shRNA (Fig. 5B,C) in order to investigate the role of RAGE in HMGB1-induced EMT. We found that RAGE knockdown blocked HMGB1-induced downregulation of E-cadherin and ZO-1 and upregulation of vimentin (Fig. 5D), suggesting that HMGB1 binding to RAGE activates downstream signaling pathways resulting in EMT induction. Additionally, HMGB1-induced $\beta$-catenin expression was inhibited by RAGE knockdown (Supplementary Figure S2B).

HMGB1-induced cell migration through the RAGE, PI3K/AKT, GSK-3 $\beta$, and $\beta$-catenin signaling pathways. Since epithelial cells show increased mobility during EMT, we investigated the cell migration activity in human airway epithelial cells following HMGB1 treatment. As shown in Fig. 6A-C, HMGB1 induced cell migration in a dose-dependent manner, but did not affect cell proliferation which analyzed by BrdU incorporation assay (Fig. 6C) and Ki-67 expression (Supplementary Figure S1E). Treatment with PI3K inhibitor, $\beta$-catenin shRNA (sh- $\beta$-catenin), and RAGE shRNA (sh-RAGE) reduced HMGB1-induced cell migration (Fig. 6D-G). Treatment with GSK-3 $\beta$ inhibitor alone induced cell migration and did not show any synergistic effect when combined with HMGB1 treatment.

\section{Discussion}

This study demonstrated that HMGB1 induced EMT, as well as cell migration, in human airway epithelial cells. In the airway, inflammation and growth factors constitute the primary factors associated with EMT induction and enhancement. Exogenous compounds, such as allergens and cigarette smoke, can induce EMT-related growth factors, such as TGF- $\beta 1$, connective tissue growth factor, and platelet-derived growth factor ${ }^{34,35}$. Increased levels of cytokines, such as IL- $1 \beta$ and TNF- $\alpha$, are also able to enhance TGF- $\beta$-induced EMT ${ }^{25-27}$. During inflammation, pro-inflammatory cytokines enhance TGF- $\beta 1$-induced EMT, however, few reports indicate that pro-inflammatory 


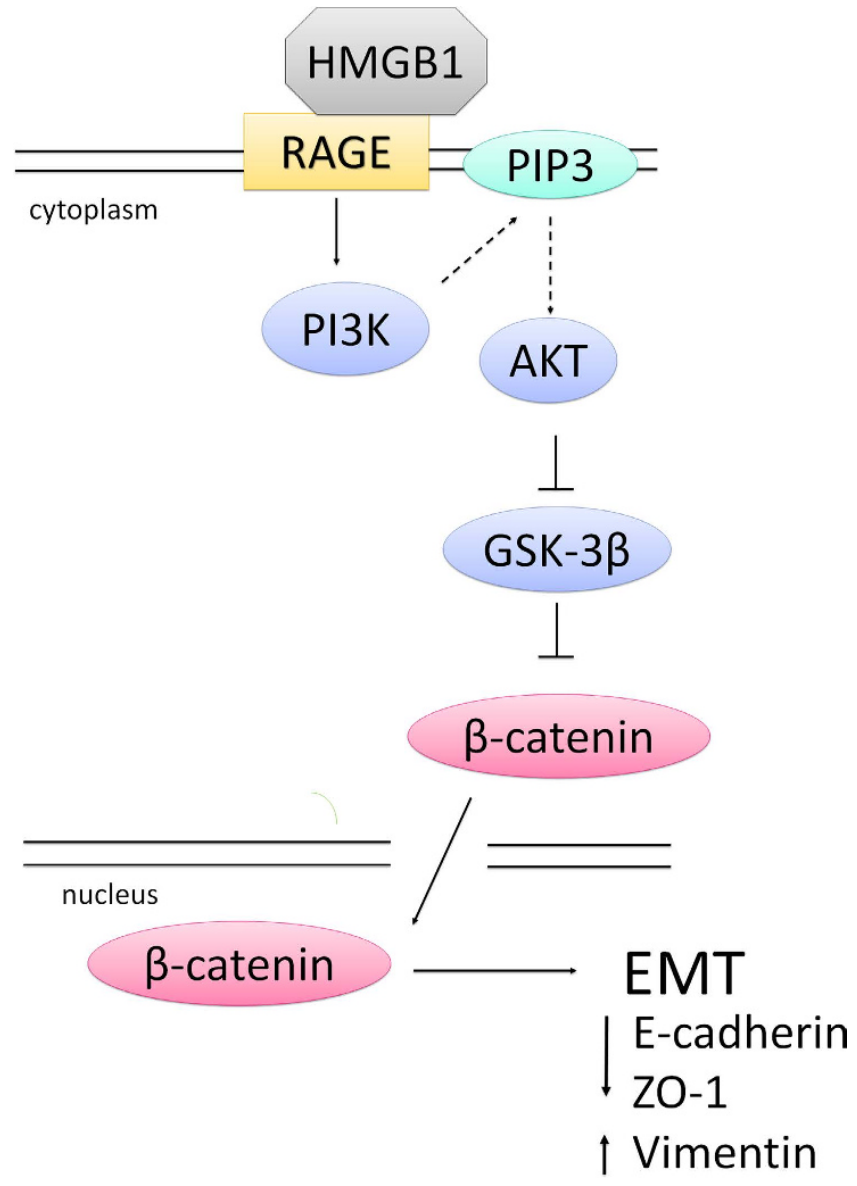

Figure 7. A model of HMGB1-induced EMT in human airway epithelial cells. HMGB1 binds RAGE to induce PI3K activation and subsequent AKT phosphorylation, GSK-3 $\beta$ inhibition, and $\beta$-catenin accumulation in the cytosol. $\beta$-catenin translocates to the nucleus and causes downregulation of $\mathrm{ZO}-1$ and E-cadherin and upregulation of vimentin, thus inducing EMT and cell migration.

cytokines are capable of inducing EMT in the absence of TGF- $\beta 1$ involvement ${ }^{36}$. In this study, we found that HMGB1 by itself can induce EMT without inducing TGF- $\beta 1$ production.

Increased HMGB1 levels were observed in COPD and asthma patients, especially in severe cases ${ }^{19,37}$. In our previous study, we found that HMGB1 was implicated in subepithelial fibrosis in a murine model of asthma ${ }^{21}$. Neutralization of lung HMGB1 using an HMGB1 antibody reduced allergen-induced collagen deposition around the airway and was accompanied by a decrease in TGF- $\beta 1$ production. Here, we used cultured human bronchial epithelial cells and demonstrated that HMGB1 directly induced EMT through activation of the PI3K/AKT/ GSK3 $\beta / \beta$-catenin signaling pathway. $\beta$-catenin is an oncoprotein that plays an important role in EMT induction. In normal epithelium, $\beta$-catenin is associated with E-cadherin, and any free cytosolic $\beta$-catenin is phosphorylated by GSK3 $\beta$ and targeted for ubiquitin-dependent degradation ${ }^{38}$. We observed that treatment of airway epithelial cells with HMGB1 resulted in inactivation of GSK3 $\beta$ by PI3K-dependent AKT phosphorylation, which caused cytoplasmic accumulation of $\beta$-catenin and its subsequent translocation to the nucleus. Accumulation of cytosolic $\beta$-catenin following HMGB1 treatment was sustained for up to $24 \mathrm{~h}$ without any observable activation of $\beta$-catenin mRNA expression. This indicated that $\beta$-catenin activation by HMGB1 might not mediate transcriptional regulation. In the nucleus, $\beta$-catenin associates with TCF4 and acts as a transcriptional activator, resulting in expression of EMT-inducing transcription factors, such as ZEB1, ZEB2, SNAI1, SNAI2, Twist1, and Twist $2^{39}$. Although we did not analyze the gene expression of all transcription factors (Table 1), we observed through RNA sequencing assays that HMGB1 treatment induced TCF4, SNAI2, and TWIST1 mRNA expression and increased Snail and Twist protein translation (Supplementary Figure S2A).

We also observed that GSK3 $\beta$ inhibition by HMGB1 was transient, whereas nuclear translocation and accumulation of $\beta$-catenin was sustained for up to $3 \mathrm{~h}$ and $24 \mathrm{~h}$, respectively. It is suggested that HMGB1 might activate other target molecules responsible for maintaining $\beta$-catenin activation and localization for extended periods. WNT signaling is an important inducer of $\beta$-catenin activation, and the WNT/ $\beta$-catenin signaling pathway initiates a signaling cascade that is crucial during normal embryonic development, maintenance of adult tissue homeostasis, and in a variety of diseases, such as cancer, fibrosis, and neurodegeneration ${ }^{40}$. Previous studies showed that HMGB1 enhanced WNT/ $\beta$-catenin signaling by increasing TCF/Lef1/ $\beta$-catenin activity in zebrafish embryos; however, the exact mechanisms involved remain unclear ${ }^{41}$. Therefore, we examined whether HMGB1 treatment would regulate WNT-associated $\beta$-catenin activation in BEAS-2B cells. HMGB1 treatment induced low-density lipoprotein 
receptor-related protein 6 phosphorylation (LRP6-p) at Ser1490 in BEAS-2B cells for up to 24h (Supplementary Figure S1D). LRP6 phosphorylation by GSK-3 $\beta$ and casein kinase 1 resulted in LRP6 recruitment of axin to the plasma membrane and activation of $\beta$-catenin ${ }^{42}$. Currently, the mechanism associated with HMGB1-induced LRP-6 activation is unknown and requires future study.

We observed through immunofluorescence staining in BEAS-2B cells that E-cadherin and ZO-1 were expressed in the cytoplasm and in the plasma membrane, while it was expected that E-cadherin and ZO-1 were predominantly localized to the plasma membrane (Supplementary Figure S1A). To confirm whether the result was due to cell-type differences, we verified E-cadherin expression and localization in human bronchial epithelial cell lines (HBE cells). Our results indicated that E-cadherin expressed and localized to both the plasma membrane and the cytoplasm, however, decreased E-cadherin expression was observed following HMGB1 treatment ( $300 \mathrm{ng} / \mathrm{mL}$ for 24 h; Supplementary Figure S1C). Previous studies have showed that E-cadherin was also expressed and localized to the cytoplasm in normal airway epithelial cells ${ }^{43,44}$. However, the reasons associated with ZO-1 and E-cadherin localization to the cytoplasm in BEAS-2B and HBE cells require further investigation.

Extracellular HMGB1 interacts with receptors, including RAGE, TLR2, and TLR4, to activate signaling pathways that cause chemotactic responses and the release of pro-inflammatory cytokines ${ }^{31-33}$. Of these receptors, RAGE is reportedly involved in HMGB1-induced cell migration and associated with lung fibrosis ${ }^{45}$. Here, we found that HMGB1 induced airway epithelial-cell migration and that EMT was primarily mediated by RAGE-HMGB1 interactions. Therefore, in addition to mediating fibrosis of the alveolar region, the RAGE-HMGB1 interaction is also involved in mesenchymal transition of airway epithelial cells, which might lead to subepithelial fibrosis. Downstream signaling pathways associated with RAGE include the Cdc42/Rac, MAPK/NF- $\kappa$ B, and PI3K/AKT pathways, all of which are involved in cell mobility ${ }^{46-48}$. In this study, we found that HMGB1 interaction with RAGE transduced PI3K/AKT activation to induce cell migration and EMT. Further investigation is needed to determine whether HMGB1-induced cell migration and EMT involves the Cdc42/Rac and/or MAPK/NF- $\kappa \mathrm{B}$ signaling pathways.

In severe asthma, dysregulated bronchial epithelium is exhibits abnormally high levels of proliferation without sufficient compensation by death signaling, which results in thickening of the epithelium and lamina reticularis and contributes to airway remodeling ${ }^{49}$. HMGB1 has been identified as an activator of airway structure alteration through cell proliferation based on previous studies reporting that HMGB1 is involved in proliferation of lung smooth muscle cells, vascular endothelial cells, and fibroblasts, implicating it in pulmonary artery and airway remodeling in acute lung injury and in chronic airway inflammatory diseases ${ }^{50-53}$. However, whether HMGB1 causes airway epithelial cell proliferation remains unclear. In our study, we found that HMGB1 did not induce human airway epithelial cell proliferation.

In conclusion, this study elucidated the role of HMGB1 in EMT in normal human airway epithelial cells (Fig. 7). EMT is an important mechanism involved in cancer cell migration and metastasis. Recently, in chronic airway diseases, such as COPD and asthma, EMT was associated with disease severity, steroid resistance, and lung dysfunction. Since steroids do not affect EMT, new agents are required to target EMT in patients with severe asthma and COPD. Our study indicated that HMGB1, a late-phase cytokine, might be a potential therapeutic target for treatment of severe cases of asthma and COPD in the future.

\section{Methods}

Cell culture. Primary normal human airway epithelial cells and immortalized normal human bronchial epithelial cell line (HBE cells) were kindly provided by Dr. Reen Wu (University of California-Davis, USA). Primary cells and culture conditions were prepared according to previous studies ${ }^{54}$. Human tracheobronchial tissues were obtained from the University of California Medical Center (Sacramento, CA, USA) with patient consent and from the National Disease Research Interchange (Philadelphia, PA, USA). The University Human Subjects Review Committee approved all procedures involved in tissue procurement. The methods were carried out in accordance with the approved guidelines. Human primary airway epithelial cells were cultured in Bronchial Epithelial Cell Growth Medium (BEGM) (Lonza Group Ltd. Basel, Switzerland). The culture conditions for HBE1 was described in previous studies ${ }^{54}$. The HBE cell line (BEAS-2B) was obtained from ATCC (Manassas, VA, USA) and maintained in Roswell Park Memorial Institute (RPMI) 1640 medium supplemented with $10 \%$ fetal bovine serum (FBS).

Recombinant protein. Recombinant human HMGB1 was purified by Escherichia coli expression system to homogeneity as previously described ${ }^{55}$. Briefly, pET28a-HMGB1 expression plasmids were kindly provided by Dr. Wen-Cheng Xiong, Department of Neurology, Medical College of Georgia (Georgia Regents University, Augusta, GA, USA). We PCR-amplified HMGB1 from human primary macrophage cDNA and inserted the amplified segment into the vectors. The plasmids were transformed into E. coli BL21(DE3) pLysS cells (Novagen, San Diego, CA, USA), which were screened on Luria-Bertani (LB) plates containing $100 \mu \mathrm{g} / \mathrm{mL}$ carbenicillin (MDBio, New Taipei City, Taiwan) and $50 \mu \mathrm{g} / \mathrm{mL}$ chloramphenicol (MDBio), and then a single colony was inoculated in the same liquid medium at $37^{\circ} \mathrm{C}$ overnight. The following day, the bacteria were subcultured in LB broth with the same concentration of the two antibiotics at $37^{\circ} \mathrm{C}$. When the $\mathrm{OD}_{600}$ value of the bacteria culture approached 0.8 , the culture was moved to a $25^{\circ} \mathrm{C}$ incubator and $0.5 \mathrm{mM}$ of isopropyl $\beta$-D-1-thiogalactopyranoside added. After a 16-h induction, the bacteria were harvested by centrifuge and suspended in $20 \mathrm{mM}$ HEPES (pH 7.9), $500 \mathrm{mM}$ $\mathrm{NaCl}, 1 \mathrm{mM}$ benzamidine, and $1 \mathrm{mM}$ phenylmethylsulfonyl fluoride. The cell suspension was sonicated, and the soluble fraction isolated by centrifugation at $12,000 \times g\left(4^{\circ} \mathrm{C}\right)$ for $30 \mathrm{~min}$. Recombinant HMGB1 was purified using an ÄKTA Prime system with a HisTrap FF column (GE Health, Uppsala, Sweden). The purified HMGB1 protein was verified by Coomassie blue staining after sodium dodecyl sulfate polyacrylamide gel electrophoresis (SDS-PAGE) analysis to verify purity $>90 \%$. To avoid endotoxin contamination, the purified HMGB1 protein was cleaned with EndoTrap (Hyglos GmbH, Germany). Activity of the recombinant human HMGB1 was 
determined by induction of TNF- $\alpha$ secretion in RAW 264.7 mouse monocyte cells. We were unaware of the post-translational modification of recombinant HMGB1. The dosages of HMGB1 (10, 100, and $300 \mathrm{ng} / \mathrm{mL}) \mathrm{used}$ in this study were according to previous work by Watanabe et al. ${ }^{19}$, which observed HMGB1 concentrations in induced sputum at ranges of $0-590 \mathrm{ng} / \mathrm{mL}(91.5 \mathrm{ng} / \mathrm{mL}$ median) in asthmatic patients and $250-600 \mathrm{ng} / \mathrm{mL}$ in severely asthmatic patients. Zhou et al. ${ }^{56}$ showed that HMGB1 concentrations in sputum were $246-356 \mathrm{ng} / \mathrm{mL}$ in asthmatic patients. Ferhani et al. ${ }^{20}$ showed that HMGB1 concentrations in bronchial lavage fluid were 20-160 ng/ $\mathrm{mL}$ in COPD patients. Therefore, HMGB1 might reach concentrations of $100 \mathrm{ng} / \mathrm{mL}$ and $300 \mathrm{ng} / \mathrm{mL}$ in the lung, especially in cases of severe asthma.

Knockdown of gene expression by shRNA. Lentiviral expressed shRNAs were purchased from the National RNAi Core Facility Platform, Taiwan. Target sequences were as follows: $\beta$-catenin, TCTAACCTCACTTGCAATAAT (shRNA1) and TTGTTATCAGAGGACTAAATA (shRNA2); RAGE, CGAGTCCGTGTCTACCAGATT (shRNA1) and GCGGCTGGAATGGAAACTGAA (shRNA2). As described previously ${ }^{22}$, cells were infected with 1 multiplicity of infection (MOI) of lentiviral expressed $\beta$-catenin shRNA and $0.5 \mathrm{MOI}$ of lentiviral expressed RAGE shRNA for $72 \mathrm{~h}$. Stable clones of shRNA-infected cells were selected by culturing in $0.5 \mu \mathrm{g} / \mathrm{mL}$ puromycin.

Cell proliferation assay. BEAS-2B cells were cultured with various concentrations of HMGB1 for $18 \mathrm{~h}$ and pulsed with 5-Bromo-2-deoxyuridine (BrdU) for an additional $6 \mathrm{~h}$. Cell proliferation was determined by BrdU incorporation assay according to manufacturer instructions (Roche Diagnostics GmbH, Roche Applied Science, Germany $)^{57}$.

Secreted active TGF- $\beta 1$ assay. Cells were treated with different doses of HMGB1 in RPMI medium contained with $1 \%$ FBS for $20 \mathrm{~h}$ and collected medium for active TGF- $\beta 1$ measurement by enzyme-linked immunosorbent assay (ELISA) according to manufacturer's instructions (R\&D Systems, Minneapolis, MN, USA).

Cell migration assay. Cell migration was determined using the scratch assay. Briefly, cells were seeded in onto a 12-well plate and incubated to confluence. A cell-free wound area was then created by scratching the cell layer with a pipette tip. Cells were treated with different concentrations of HMGB1 and allowed to migrate into the cell-free wound in RPMI containing $1 \%$ FBS for $16 \mathrm{~h}$.

Immunofluorescence staining of EMT markers. Immunofluorescence staining of cellular protein was performed as described previously ${ }^{58}$. Briefly, cells cultured on cover slips were treated with different concentrations of HMGB1 for $16 \mathrm{~h}$. Cells were fixed with $4 \%$ paraformaldehyde and stained using anti-E-cadherin Ab (Abcam, Cambridge, UK; UK Catalog No: ab40772), anti-ZO-1 Ab (Abcam; Catalog No: ab59720), and anti-vimentin (Sigma Aldrich, St. Louis, MO, USA; Catalog No: V6389 ) antibodies, while 4' 6 -diamidino-2-phenylindole was used for nuclear staining (Calbiochem, San Diego, CA, USA). Cells were then incubated with a secondary antibody, Alexa Fluor 488-conjugated goat anti-mouse IgG (Jackson ImmunoResearch Laboratories Inc., Amish, PA, USA). Stained cells were imaged using a fluorescence and confocal microscope (Zeiss: Carl Zeiss, Göttingen, Germany). Fluorescence intensity was quantified using ImageJ software (http://imagej.nih.gov/ij/). The methods used to quantify the fluorescence density involved three steps: 1) count the fluorescence mean density, 2) divide the cell numbers, and 3 ) divide the control mean.

RNA sequencing assay. Total RNA was extracted from cells using TRIzol reagent (Invitrogen, Carlsbad, CA, USA) according to manufacturer instructions. RNA integrity was determined using the RNA6000 Nano kit on the Agilent 2100 Bioanalyzer (Agilent, Santa Clara, CA, USA). RNA libraries were prepared using the low-throughput protocol of the Illumina TruSeq RNA sample preparation kit (Illumina, San Diego, CA, USA). Briefly, $1 \mu \mathrm{g}$ of total RNA was used for poly-A mRNA selection, and selected mRNA was then fragmented in high-salt and high-temperature conditions. cDNA synthesis, end-repair, A-tailing, multiplex indexing, and PCR amplification was performed and the resulting libraries were quantified and analyzed on a HiSeq2000 (Illumina) for SR50. The resulting reads were aligned to the $\mathrm{Hg} 19$ transcriptome. Data analysis was completed using DESeq version $1.6 .1^{59}$

Quantitative real-time PCR. RNA was converted into cDNA and then measured by quantitative real-time PCR using ABI PRISM 7900 Sequence Detector (Applied Biosystems, Foster City, CA, USA). The PCR product was amplified using SyBr Green regents. Statistically significant increases in target genes were determined using the threshold cycle (Ct) normalized with GADPH, and the expression level was reported as fold change using the 2-ddCT method ${ }^{60}$. The primer sequences used were as follows: E-cadherin, CCTGGGACTCCACCTACAGA (forward) and TGGATTCCAGAAACGGAGGC (reverse); ZO-1, GCCTCTCAACAGAAAGCAGAA (forward) and TGCCTCATCATTTCCTCGGG (reverse); vimentin, GACAATGCGTCTCTGGCACGTCTT (forward) and AAGAACCTGCAGGAGGCAGAAGAA (reverse); GADPH, TGCACCACCAACTGCTTAGC (forward) and TCTTCTGGGTGGCAGTGATG (reverse).

Nuclear-extract preparation. After incubation with HMGB1 $(300 \mathrm{ng} / \mathrm{mL})$ for different periods, cells were washed twice with ice-cold phosphate-buffered saline (PBS). Cells were then scraped from the dishes and nuclear protein was extracted using NE-PER nuclear and cytoplasmic extraction kit according to manufacturer recommendations (Pierce, Rockford, IL, USA). 
Western blot analysis. The protein concentration of cell and tissue lysates was determined using a Bio-Rad protein assay kit (Bio-Rad, Richmond, CA, USA) according to manufacturer instructions. Immunoblotting was performed as described previously. Proteins were separated by SDS-PAGE, which was performed on $10 \%$ polyacrylamide gels, and then transferred onto polyvinylidene difluoride membranes (PerkinElmer Life Sciences, Boston, MA, USA) using the Panther ${ }^{\mathrm{TM}}$ Semidry Electroblotter (Owl Scientific, Portsmouth, NH, USA). The blot was incubated overnight with blocking solution (5\% skim milk) at $4{ }^{\circ} \mathrm{C}$ and then incubated with different primary antibodies (1:1000 dilution), including anti-E-cadherin Ab (Abcam), anti-ZO-1 Ab (Abcam), anti-vimentin (Sigma Aldrich), anti-Akt1-phospho (pS473) (Abcam; Catalog No: 2118-1), Anti-Akt (Abcam; Catalog No: 1085-1), anti-GSK-3 $\beta$ Phospho (Abcam; Catalog No: 2435-1), GSK-3 $\beta$ (Santa Cruz Biotechnology, Santa Cruz, CA, USA; Catalog No: sc-9166), RAGE (GeneTex, Irvine, CA, USA; Catalog No: GTX23611), TLR2 (Abcam; Catalog No: T0337), TLR4 (Abcam; Catalog No: T0324), $\beta$-Catenin (BD Transduction Lab., San Jose, CA, USA: Catalog No: 610154), $\beta$-actin (Sigma Aldrich; Catalog No: A5441), TGF $31(L A P)$ (GeneTex , Catalog No: GTX10630), GADPH (Novus, Littleton, CO, USA; Catalog No: NB300-221), Ki-67 (Bioledgend, CA, USA, Catalog No: 652401) and LRP6 phospho (Cell Signaling Technology, Danvers, MA, USA; Catalog No: 2568). After washing with Tris-buffered saline and Tween 20 (TBST), blots were incubated with horseradish peroxidase-conjugated secondary antibodies (Jackson ImmunoResearch) in TBST and developed using an enhanced chemiluminescence-detection system (PerkinElmer, Waltham, MA, USA).

Statistical analysis. All values were expressed as mean $\pm \mathrm{SD}(\mathrm{n} \geq 3)$ and analyzed using one-way analysis of variance, followed by Newman-Keuls post-hoc comparison. A $p<0.05$ was considered statistically significant.

\section{References}

1. Kalluri, R. \& Weinberg, R. A. The basics of epithelial-mesenchymal transition. J. Clin. Invest. 119, 1420-1428 (2009).

2. Zeisberg, M. \& Neilson, E. G. Biomarkers for epithelial-mesenchymal transitions. J. Clin. Invest. 119, 1558-8238 (Electronic) (2009).

3. Bartis, D., Mise, N., Mahida, R. Y., Eickelberg, O. \& Thickett, D. R. Epithelial-mesenchymal transition in lung development and disease: does it exist and is it important? Thorax 69, 760-765 (2014).

4. Pain, M. et al. Tissue remodelling in chronic bronchial diseases: from the epithelial to mesenchymal phenotype. Eur. Respir. Rev. 23, 118-130 (2014).

5. Sidhu, S. S. et al. Roles of epithelial cell-derived periostin in TGF-beta activation, collagen production, and collagen gel elasticity in asthma. Proc. Natl. Acad. Sci. USA 107, 14170-14175 (2010).

6. Heijink, I. H. et al. Down-regulation of E-cadherin in human bronchial epithelial cells leads to epidermal growth factor receptordependent Th2 cell-promoting activity. J. Immunol 178, 7678-7685 (2007).

7. Bergeron, C., Al-Ramli, W. \& Hamid, Q. Remodeling in Asthma. Pro. Am. Thorac. Soc. 6, 301-305 (2009).

8. Chakir, J. et al. Airway remodeling-associated mediators in moderate to severe asthma: effect of steroids on TGF-beta, IL-11, IL-17, and type I and type III collagen expression. J. Allergy Clin. Immunol. 111, 1293-1298 (2003).

9. Hackett, T. L. Epithelial-mesenchymal transition in the pathophysiology of airway remodelling in asthma. Curr. Opin. Allergy Clin. Immunol. 12, 53-59 (2012).

10. Milara, J., Peiro, T., Serrano, A. \& Cortijo, J. Epithelial to mesenchymal transition is increased in patients with COPD and induced

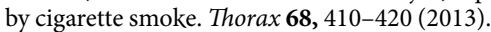

11. Davies, D. E. The role of the epithelium in airway remodeling in asthma. Proc. Am. Thorac. Soc. 6, 678-682 (2009).

12. Shifren A., Witt, C., Christie, C. \& M., C. Mechanisms of Remodeling in Asthmatic Airways. J. Allergy 2012 (2012).

13. Goleva, E., Hauk, P. J., Boguniewicz, J., Martin, R. J. \& Leung, D. Y. Airway remodeling and lack of bronchodilator response in steroidresistant asthma. J. Allergy Clin. Immunol. 120, 1065-1072 (2007).

14. Holgate, S. T. et al. Understanding the pathophysiology of severe asthma to generate new therapeutic opportunities. J. Allergy Clin. Immunol. 117, 496-506 (2006).

15. Goodwin, G. H., Sanders, C. \& Johns, E. W. A new group of chromatin-associated proteins with a high content of acidic and basic amino acids. Eur. J. Biochem. 38, 14-19 (1973).

16. Andersson, U. et al. High mobility group 1 protein (HMG-1) stimulates proinflammatory cytokine synthesis in human monocytes. J. Exp. Med.192, 565-570 (2000).

17. Kokkola, R. et al. RAGE is the major receptor for the proinflammatory activity of HMGB1 in rodent macrophages. Scand. J. Immunol. 61, 1-9 (2005).

18. Park, J. S. et al. Activation of gene expression in human neutrophils by high mobility group box 1 protein. Am. J. Physiol.Cell Physiol.284, C870-879 (2003).

19. Watanabe, T. et al. Increased levels of HMGB-1 and endogenous secretory RAGE in induced sputum from asthmatic patients. Respir. Med. 105, 519-525 (2011).

20. Ferhani, N. et al. Expression of high mobility group box 1 and receptor for advanced glycation end products in COPD. Am. J. Respir. Crit. Care Med 181, 917-927 (2010).

21. Lee, C. C. et al. Inhibition of high-mobility group box 1 in lung reduced airway inflammation and remodeling in a mouse model of chronic asthma. Biochem. Pharmacol. 86, 940-949 (2013).

22. Lee, C. C., Wang, C. N., Lee, Y. L., Tsai, Y. R. \& Liu, J. J. High mobility group box 1 induced human lung myofibroblasts differentiation and enhanced migration by activation of mmp-9. PLoS One 10, e0116393 (2015).

23. Zeisberg, M. \& Neilson, E. G. Biomarkers for epithelial-mesenchymal transitions. The Journal of clinical investigation 119, 1429-1437 (2009).

24. Roy, S. et al. Significance of PELP1 in ER-negative breast cancer metastasis. Mol. Cancer Res. 10, 25-33 (2012).

25. Doerner, A. M. \& Zuraw, B. L. TGF- $\beta$ (1 )induced epithelial to mesenchymal transition (EMT) in human bronchial epithelial cells is enhanced by IL-1 $\beta$ but not abrogated by corticosteroids. Respir. Res. 10, 100-100 (2009).

26. Erzurum, S. C. Inhibition of Tumor Necrosis Factor $\alpha$ for Refractory Asthma. N. Engl. J. Med. 354, 754-758 (2006).

27. Camara, J. \& Jarai, G. Epithelial-mesenchymal transition in primary human bronchial epithelial cells is Smad-dependent and enhanced by fibronectin and TNF-alpha. Fibrogenesis Tissue Repair 3, 2 (2010).

28. Kalluri, R. \& Weinberg, R. A. The basics of epithelial-mesenchymal transition. J. Clin.Invest. 119, 1420-1428 (2009).

29. Manning, B. D. \& Cantley, L. C. AKT/PKB signaling: navigating downstream. Cell 129, 1261-1274 (2007).

30. Zheng, H. et al. Glycogen synthase kinase-3 beta regulates Snail and beta-catenin expression during Fas-induced epithelialmesenchymal transition in gastrointestinal cancer. Eur. J. Cancer 49, 2734-2746 (2013).

31. Wang, H., Ward, M. F. \& Sama, A. E. Novel HMGB1-inhibiting therapeutic agents for experimental sepsis. Shock 32, 348-357 (2009).

32. Yang, H., Wang, H., Christopher, J. C. \& Tracey, K. J. The cytokine activity of HMGB1. J. Leuko. Biol. 78, 1-8 (2005).

33. Ivanov, S. et al. A novel role for HMGB1 in TLR9-mediated inflammatory responses to CpG-DNA. Blood 110, 1970-1981 (2007). 
34. Churg, A., Tai, H., Coulthard, T., Wang, R. \& Wright, J. L. Cigarette smoke drives small airway remodeling by induction of growth factors in the airway wall. Am. J. Respir. Crit. Care Med. 174, 1327-1334 (2006).

35. Heijink, I. H., Postma, D. S., Noordhoek, J. A., Broekema, M. \& Kapus, A. House dust mite-promoted epithelial-to-mesenchymal transition in human bronchial epithelium. Am. J. Respir. Cell Mol. Biol. 42, 69-79 (2010).

36. Mikami, Y. et al. Tumor necrosis factor superfamily member LIGHT induces epithelial-mesenchymal transition in A549 human alveolar epithelial cells. Biochem. Biophys. Res. Commun. 428, 451-457 (2012).

37. Hou, C. et al. High mobility group protein B1 (HMGB1) in Asthma: comparison of patients with chronic obstructive pulmonary disease and healthy controls. Mol. Med. 17, 807-815 (2011).

38. Clevers, H. Wnt/beta-catenin signaling in development and disease. Cell 127, 469-480 (2006).

39. Polyak, K. \& Weinberg, R. A. Transitions between epithelial and mesenchymal states: acquisition of malignant and stem cell traits. Nat. Rev. Cancer 9, 265-273 (2009).

40. Anastas, J. N. \& Moon, R. T. WNT signalling pathways as therapeutic targets in cancer. Nat. Rev. Cancer 13, 11-26 (2013).

41. Itou, J. et al. HMGB factors are required for posterior digit development through integrating signaling pathway activities. Developmental Dynamics .240, 1151-1162 (2011).

42. Zeng, X. et al. A dual-kinase mechanism for Wnt co-receptor phosphorylation and activation. Nature 438, 873-877 (2005).

43. Wu, Z. et al. Detection of epithelial to mesenchymal transition in airways of a bleomycin induced pulmonary fibrosis model derived from an alpha-smooth muscle actin-Cre transgenic mouse. Respir. Res. 8, 1 (2007).

44. Furukawa, M., Wheeler, S., Clark, A. M. \& Wells, A. Lung Epithelial Cells Induce Both Phenotype Alteration and Senescence in Breast Cancer Cells. PLoS ONE 10, e0118060 (2015).

45. Buckley, S. T. \& Ehrhardt, C. The receptor for advanced glycation end products (RAGE) and the lung. J. Biomed. Biotechnol. 2010, 917108 (2010).

46. Toure, F. et al. Receptor for advanced glycation end-products (RAGE) modulates neutrophil adhesion and migration on glycoxidated extracellular matrix. Biochem. J. 416, 255-261 (2008).

47. Palumbo, R. et al. Cells migrating to sites of tissue damage in response to the danger signal HMGB1 require NF- $\mathrm{B}$ activation. J. Cell. Biol. 179, 33-40 (2007).

48. Huttunen, H. J., Fages, C. \& Rauvala, H. Receptor for advanced glycation end products (RAGE)-mediated neurite outgrowth and activation of NF-kappaB require the cytoplasmic domain of the receptor but different downstream signaling pathways. J. Biol. Chem. 274, 19919-19924 (1999).

49. Cohen, L. et al. Epithelial cell proliferation contributes to airway remodeling in severe asthma. Am. J. Respir. Crit. Care Med. 176, 138-145 (2007).

50. Hamada, N. et al. The role of high mobility group box1 in pulmonary fibrosis. Am. J. Respir. Cell Mol. Biol. 39, 440-447 (2008).

51. Hou, C. et al. HMGB1 contributes to allergen-induced airway remodeling in a murine model of chronic asthma by modulating airway inflammation and activating lung fibroblasts. Cell Mol. Immunol. 12, 409-423 (2015).

52. Wang, H. L. et al. HMGB1 enhances smooth muscle cell proliferation and migration in pulmonary artery remodeling. Int. J. Clin. Exp. Pathol. 7, 3836-3844 (2014).

53. Zabini, D. et al. High-mobility group box-1 induces vascular remodelling processes via c-Jun activation. J.Cell Mol. Med. (2015).

54. Fujisawa, T. et al. NF-kappaB mediates IL-1beta- and IL-17A-induced MUC5B expression in airway epithelial cells. Am. J. Respir. Cell Mol.Biol. 45, 246-252 (2011)

55. Yang, H. et al. A critical cysteine is required for HMGB1 binding to Toll-like receptor 4 and activation of macrophage cytokine release. Proc. .Natl. Acad. Sci. 107, 11942-11947 (2010).

56. Zhou, Y. et al. HMGB1 and RAGE levels in induced sputum correlate with asthma severity and neutrophil percentage. Hum. Immunol. 73, 1171-1174 (2012).

57. Rao, Y. K. et al. Ovatodiolide inhibits the maturation of allergen-induced bone marrow-derived dendritic cells and induction of Th2 cell differentiation. Int. immunopharmacol. 17, 617-624 (2013).

58. Lin, C. D. et al. Zinc oxide nanoparticles impair bacterial clearance by macrophages. Nanomedicine 9, 1327-1339 (2014).

59. Anders, S. \& Huber, W. Differential expression analysis for sequence count data. Genome Biol. 11, R106 (2010).

60. Lee, C. C. et al. Antiallergic asthma properties of brazilin through inhibition of TH2 responses in T cells and in a murine model of asthma. J. Agric. Food Chem. 60, 9405-9414 (2012).

\section{Acknowledgements}

This study was supported by the National Science Council in Taiwan (NSC 101-2320-B-039-047, NSC 102-2918I-039-002) and (CMU102-BC-10, CMU103-S-49).

\section{Author Contributions}

Y.-C.C. performed most of the experiments; S.S. performed the RNA sequencing experiments; R.W. provided input on experimental designs; H.-T.C. performed generation of recombinant HMGB1; C.-N.W. performed the western blot assay; J.-W.L. and W.-C.S. provided technological support; C.-C.L. provided input on experiment design and manuscript writing.

\section{Additional Information}

Supplementary information accompanies this paper at http://www.nature.com/srep

Competing financial interests: The authors declare no competing financial interests.

How to cite this article: Chen, Y.-C. et al. High mobility group box 1-induced epithelial mesenchymal transition in human airway epithelial cells. Sci. Rep. 6, 18815; doi: 10.1038/srep18815 (2016).

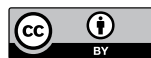

This work is licensed under a Creative Commons Attribution 4.0 International License. The images or other third party material in this article are included in the article's Creative Commons license, unless indicated otherwise in the credit line; if the material is not included under the Creative Commons license, users will need to obtain permission from the license holder to reproduce the material. To view a copy of this license, visit http://creativecommons.org/licenses/by/4.0/ 